\title{
Biopolymer blends for mechanical property gradient 3D printed parts
}

\author{
L. Jeantet ${ }^{1}$, A. Regazzi ${ }^{2}$, A. Taguet ${ }^{3}$, M. F. Pucci ${ }^{2}$, A.-S. Caro ${ }^{2}$, J.-C. Quantin ${ }^{2}$ \\ ${ }^{1}$ Segula Technologies, 19 rue d'Arras, 92000 Nanterre, France \\ ${ }^{2}$ LMGC, IMT Mines Ales, Univ Montpellier, CNRS, Ales, France \\ ${ }^{3}$ Polymers Composites and Hybrids (PCH), IMT Mines Ales, Ales, France
}

Received 5 May 2020; accepted in revised form 9 July 2020

\begin{abstract}
This study evaluated the potential of using poly(lactic acid)/poly(e-caprolactone) (PLA/PCL) blends for fused filament fabrication (FFF) and assembly with pure PLA for biomedical applications. PLA/PCL binary blends were meltblended in a twin-screw extruder at different ratios (20/80 to 80/20) and then formed into filaments with a calibrated diameter for FFF. The microstructure, surface properties, and rheological and mechanical behaviors of the blends were assessed. The blends were immiscible but showed signs of adhesion between the phases. It was determined that the fibrillar morphology of inclusions for PLA/PCL ratios higher than 30/70 proved to be driven by the manufacturing process. The tensile mechanical behaviors of printed and injected samples were similar, and their Young's modulus was simulated using Halpin-Tsai and Mori Tanaka models based on the sample microstructure. The ductility of the blends was strongly driven by the behavior of its majority phase. Finally, specific samples were designed to characterize the tensile strength between PLA and its blends by entangling layers of both materials. The strength of the assembly was found to be dependent on the phase that was continuous and was governed by the strength and the viscosity of the blend.
\end{abstract}

Keywords: polymer blends and alloys, material extrusion, interface, poly(lactic acid), poly(e-caprolactone)

\section{Introduction}

Poly(lactic) acid (PLA) is a bio-based, biodegradable, and biocompatible polymer. It is widely used in Fused Filament Fabrication (FFF) due to its ease of processability, related to its thermal properties. Its rheological properties and low shrinkage are appropriate for accurate deposition of fused filaments and facilitate good geometrical accuracy of printed parts. Although this polymer has high stiffness, it is a brittle material and exhibits very low toughness. This limitation can be addressed by blending PLA with ductile polymers such as poly ( $\varepsilon$-caprolactone) (PCL) to produce a hightoughness and high-flexibility material [1]. PCL is a biocompatible and biodegradable oil-based polymer. Given that these characteristics are critical in most applications of PLA, PCL is a potential option with respect to the preparation of a material with enhanced properties. This polymer is already used in the development of tissue replacement scaffolds technologies [2] and biodegradable packaging.

The blending of biodegradable aliphatic polyesters has attracted significant attention in the last decade because they offer a more environmentally sustainable alternative to traditional polymers. They are particularly useful for biomedical applications [2] given that most braces, orthoses, and prostheses are made of non-recyclable polymers [3] and have a very limited lifespan [4]. These biodegradable polymers have contrasting properties. Therefore, blending is exploited as a simple approach for creating new materials with mechanical behavior that can be tuned by adjusting the ratios of the blends $[5,6]$. 
In particular, in the case of poly(lactic acid) and poly( $\varepsilon$-caprolactone), the increase in the PCL content results in the toughening of the brittle PLA matrix. A higher toughness was achieved for the processing of 80/20 PLA/PCL blends with a high-viscosity PLA matrix [7]. Several studies have already extensively investigated the morphologies, mechanical properties, and rheological behavior of these blends in injected parts [8-11]. It was observed that PLA and PCL are thermodynamically incompatible and form a binary immiscible blend without chemical interaction between the phases. Moreover, it appears that the blending ratio, processing method, interfacial tension of the blend, and viscosity ratio significantly affect the crystallinity of each component, as well as the morphology of the blend [7]. These factors substantially influence the mechanical behavior of the blends $[8,12,13]$. To date, theoretical models have been successfully applied to predict Young's moduli of injected parts [6].

Separated PLA and PCL polymers have also been used as multi-materials for fused deposition modeling (FDM) in a single-layer temperature-adjusting transition (SLTAT) method [14]. In this report, the authors studied the effects of the temperature of the PCL bonding layer (the PCL layer above the PLA layer) on the tensile strength. Usually, the poor adhesion between sections made of different materials is a major drawback in multi-material 3D printed parts $[14,15]$. Poor interfacial adhesion is mainly due to incompatibility between the different filaments made of different polymers. This mitigates optimal diffusion leading to both reduced mechanical properties [16] and significant risk of delamination [17].

This study aims at enhancing the FFF of biodegradable, biocompatible, and highly customizable multimaterial parts intended for biomedical applications, such as casts or orthoses. In particular, it focuses on improving the bonding between materials having bad affinities (e.g. PLA and PCL). Two complementary methods are proposed to achieve this goal: i) a physico-chemical method that consists in using PLA/PCL blends in order to improve their compatibility with PLA and ii) a mechanical method that consists in creating an interpenetrating structure in order to improve the contact surface between the two materials. Combining these methods would form gradients of mechanical properties, which could result in stronger and more durable interfaces $[18,19]$ between blends and PLA regions for a potential biomedical device.
However, to the best of our knowledge, there are no published reports on the use of PLA/PCL blends for additive manufacturing, especially FFF technology. That is the reason why this study evaluated the potential of using PLA/PCL blends and interpenetrating layers with PLA in order to enhance bonding between these materials.

\section{Experimental}

\subsection{Materials}

PLA 3D850 was used in this study. It is a 3D printing grade material from NatureWorks (USA) with a melt flow rate of $7-9 \mathrm{~g} / 10 \mathrm{~min}$ at $210^{\circ} \mathrm{C} 2.16 \mathrm{~kg}$ and a density of $1.25 \mathrm{~g} / \mathrm{cm}^{3}$. CAPA ${ }^{\mathrm{TM}} 6800$ from Perstorp $\mathrm{AB}$ (Sweden) was used as PCL with a melt flow rate of $4.03-2.01 \mathrm{~g} / 10 \mathrm{~min}$ at $160^{\circ} \mathrm{C} 5 \mathrm{~kg}$, a density of $1.14 \mathrm{~g} / \mathrm{cm}^{3}$ and a mean molecular weight of $80000 \mathrm{~g} / \mathrm{mol}$. Both materials were dried overnight in a dehumidifier before processing, at $70^{\circ} \mathrm{C}$ for the PLA and $50^{\circ} \mathrm{C}$ for the PCL to prevent any humidity-related degradation. Blends of ratio 20/80, 30/70, $40 / 60,50 / 50,60 / 40,70 / 30$ and $80 / 20$ of PLA/PCL were produced by melt-blending in a BC21 $900 \mathrm{~mm}$ twin-screw extruder from Clextral (France) with an $L / D$ ratio of 36 at temperatures of $150,160,170$, $170,180,180,190^{\circ} \mathrm{C}$ and $160 \mathrm{rpm}$. Extrudates were cooled in a water bath and then pelletized.

\subsection{Processing}

\subsubsection{Filament preparation}

Blend pellets were dried overnight in a dehumidifier at $45^{\circ} \mathrm{C}$. Filaments of $2.85 \pm 0.02 \mathrm{~mm}$ calibrated diameter were produced with a dedicated Yvroud (France) line using the same processing temperature as during twin-screw extrusion. The production line was equipped with a single screw extruder (H2528), a cooling bath (BAI-3000), a crossed laser diameter sensor (ODAC 15XY), a controlled pulling system (AR03-35) and a winding tool (CY600-1-SP).

\subsubsection{Fused filament fabrication}

Filaments were used with an A4v3 FFF printer from $3 n t r$ (Italy). All printed specimens were shaped to meet the ISO 527-2 standard (1 A dog-bone samples) with a $100 \%$ filling ratio and $200 \mu \mathrm{m}$ layers. Filaments from two successive layers formed a sequence of $+45^{\circ} /-45^{\circ}$ with respect to the longitudinal direction of the samples. The horizontal nozzle speed was set to $40 \mathrm{~mm} / \mathrm{s}$. Some printing parameters such as the printing speed and the retraction length and the 
Table 1. Printing parameters for each blending ratio used in bi-material and mono-material specimens.

\begin{tabular}{|c|c|c|c|c|}
\hline PLA/PCL & $\begin{array}{c}\text { Printing } \\
\text { temperature } \\
{\left[{ }^{\circ} \mathbf{C}\right]}\end{array}$ & $\begin{array}{c}\text { Printing } \\
\text { speed } \\
{[\mathbf{m m} / \mathbf{m i n}]}\end{array}$ & $\begin{array}{c}\text { Retraction } \\
\text { length } \\
{[\mathbf{m m}]}\end{array}$ & $\begin{array}{c}\text { Extrusion } \\
\text { multiplier } \\
{[-]}\end{array}$ \\
\hline $0 / 100$ & 95 & 30 & 12 & 1.4 \\
\hline $20 / 80$ & 175 & 30 & 12 & 1.4 \\
\hline $30 / 70$ & 180 & 30 & 10 & 1.3 \\
\hline $40 / 60$ & 180 & 30 & 8 & 1.2 \\
\hline $50 / 50$ & 185 & 30 & 6 & 1.2 \\
\hline $60 / 40$ & 190 & 40 & 6 & 1.1 \\
\hline $70 / 30$ & 190 & 40 & 6 & 1.1 \\
\hline $80 / 20$ & 195 & 60 & 6 & 1.0 \\
\hline $100 / 0$ & 210 & 60 & 6 & 1.0 \\
\hline
\end{tabular}

extrusion multiplier were adjusted for each blend according to Table 1 in order to allow optimal printing quality.

Specimens made of pure PLA, pure PCL, and their blends were manufactured via FFF and injection molding to determine the intrinsic mechanical properties of the materials and to assess the influence of the process. These specimens are hereafter referred to as 'mono-materials'.

From the perspective of improving adhesion between PLA and PLA/PCL blends in multi-material printed parts, it was decided to design a transition region where layers of PLA alternate with layers of blends. The purpose is to design a structure that could be realistically used in bi-material FFF parts in order to connect PLA with its blends by creating a gradient of mechanical properties between these two materials. The mechanical properties of this structure were assessed by printing specimens consisting of an alternating superposition of PLA and blend layers over the entire surface of the sample (cf. Figure 1). The specimens using this pattern will be hereafter referred to as 'alternated bi-material' specimens.

Finally, some samples were designed in order to assess the strength between PLA and PLA/PCL blends in multi-material parts. In this perspective, samples were divided into two regions (cf. Figure 2). One end of the sample was made of pure PLA, while the other end was made of the blend. These two regions were connected via a $10 \mathrm{~mm}$ long interpenetrating structure in which layers of each material are alternated identically to the alternated bi-material specimens. Doing so increases the contact surface area between the two materials and creates a gradient of mechanical properties between PLA and its blends.

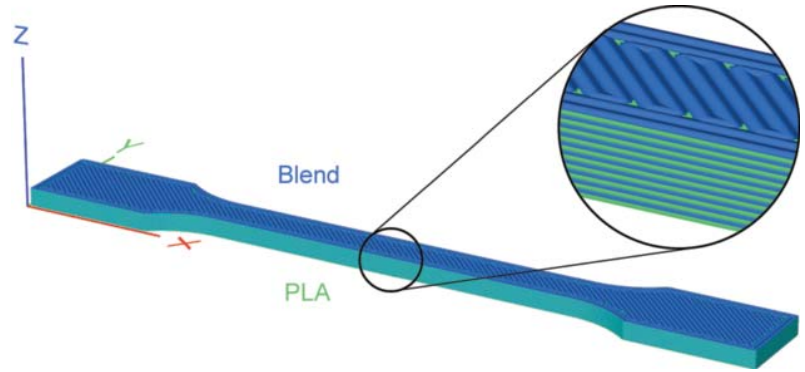

Figure 1. FFF filling pattern of alternated bi-material specimens.

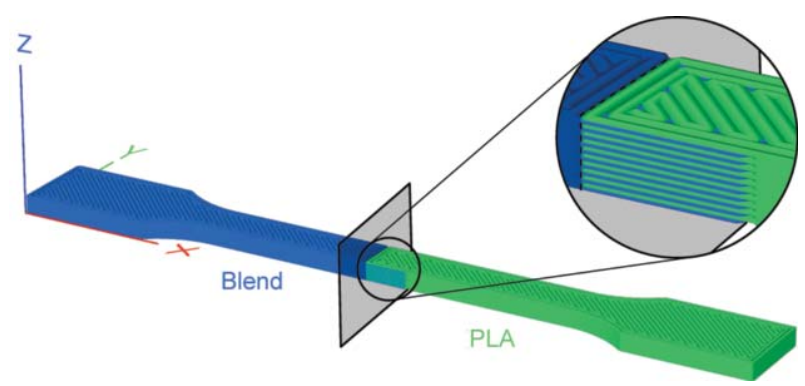

Figure 2. FFF filling pattern of bi-material gradient specimens.

The specimens using this pattern will be hereafter referred to as 'bi-material gradient' specimens. It is worth noting that they allow assessing the behavior of the assembly only. They do not provide reliable information on the intrinsic mechanical properties of the interpenetrating structure, which is given by the alternated bi-material specimens mentioned above.

\subsection{Characterization}

\subsubsection{Differential scanning calorimetry}

The characterization of blend phase transitions was conducted via Differential Scanning Calorimetry with a Diamond DSC apparatus from Perkin-Elmer (USA). Samples were heated to $200{ }^{\circ} \mathrm{C}$ and then annealed for $5 \mathrm{~min}$ to erase their thermal history. They were then cooled to $-20^{\circ} \mathrm{C}$ at $10^{\circ} \mathrm{C} / \mathrm{min}$ prior to heating again to $200^{\circ} \mathrm{C}$ at $10^{\circ} \mathrm{C} / \mathrm{min}$. The degree of crystallinity $\chi_{\mathrm{c}}$ of the PLA phase was calculated using Equation (1):

$\chi_{\mathrm{c}}[-]=\frac{H_{\mathrm{m}}-H_{\mathrm{c}}}{w \cdot H_{\mathrm{m}}^{0}}$

where $H_{\mathrm{m}}, H_{\mathrm{c}}$, and $H_{\mathrm{m}}^{0}$ are the experimental melting enthalpy, experimental cold crystallization enthalpy, and melting enthalpy of $100 \%$ crystalline PLA, respectively, and $w$ is the weight fraction of the material in the blend. The enthalpy of fusion of $100 \%$ crystalline PLA was assumed to be $91 \mathrm{~J} / \mathrm{g}$ [20]. 


\subsubsection{Scanning electron microscopy}

The morphology of the blends was observed using an FEI Quanta 200 FEG scanning electron microscope (SEM) operating at $4 \mathrm{kV}$. The samples consisting of small sections of printable polymer filament were cryogenically fractured orthogonal to the filament axis, and the surfaces obtained were then carbon coated prior to observation. Filaments of the PLA40/PCL60, PLA50/PCL50, and PLA60/PCL40 blends were also cryo-fractured along the axis of the filament and then etched with tetrahydrofuran prior to coating and observation.

\subsubsection{Atomic force microscopy}

The microstructure of filaments of PLA60/PCL40 for FFF was also observed via an MFP-3D atomic force microscope (AFM) from Asylum Research. This facilitated a more detailed observation of the morphology of the phases for this blending ratio. Samples were prepared using an ultra-cryo-microtome EM UC7 from Leica Microsystems to obtain surfaces as flat as possible for AFM analysis. Surfaces were characterized in tapping mode at a scan rate of $1 \mathrm{~Hz}$ by using a silicon probe (AC160TS-R3).

\subsubsection{Analysis of the interfacial tension}

The contact angles of three different test liquids with PLA and PCL were measured at $20^{\circ} \mathrm{C}$ using a Krüss DSA30 goniometer. The test liquids were water (high polarity), diiodomethane, (completely dispersive), and ethylene glycol (intermediate polarity and dispersivity). Table 2 shows the surface tensions, polar and dispersive components of the test liquids [21].

Measurements of contact angles of the sessile drops were performed on the smooth side of FFF printed tensile specimens (build plate side). Three sessile drop tests were performed for each liquid and each material. The obtained contact angles were used to determine the polar $\left(\gamma_{\mathrm{S}}^{\mathrm{p}}\right)$, dispersive $\left(\gamma_{\mathrm{S}}^{\mathrm{d}}\right)$, and total $\left(\gamma_{S}\right)$ surface energies of both materials (PLA and PCL) using the Owens-Wendt model (Equation (2)) $[22,23]$ :

Table 2. Surface tension and components of test liquids.

\begin{tabular}{|l|c|c|c|}
\hline \multicolumn{1}{|c|}{ Liquid } & $\begin{array}{c}\gamma_{\mathbf{L}}^{\mathbf{d}} \\
{[\mathbf{m} \mathbf{N}]}\end{array}$ & $\begin{array}{c}\gamma_{\mathbf{L}}^{\mathbf{p}} \\
{[\mathbf{m} \mathbf{N} / \mathbf{m}]}\end{array}$ & $\begin{array}{c}\gamma_{\mathbf{L}} \\
{[\mathbf{m N} / \mathbf{m}]}\end{array}$ \\
\hline Water & 21.8 & 51.0 & 72.8 \\
\hline Diiodomethane & 50.8 & 0.0 & 50.8 \\
\hline Ethylene glycol & 29.0 & 19.0 & 48.0 \\
\hline
\end{tabular}

$$
\underbrace{\frac{\gamma_{L}(1+\cos \theta)}{2 \sqrt{\gamma_{L}^{d}}}}_{y}=\sqrt{\gamma_{S}^{\mathrm{p}}} \underbrace{\frac{\sqrt{\gamma_{L}^{\mathrm{p}}}}{\sqrt{\gamma_{L}^{\mathrm{d}}}}}_{x}+\sqrt{\gamma_{\mathrm{S}}^{\mathrm{d}}}
$$

The surface energies and components were then used to calculate the interfacial tension between PLA (1) and PCL (2) via the equation proposed by $\mathrm{Wu}$ (Equation (3)) [24]:

$$
\gamma_{\mathrm{S}_{1} \mathrm{~S}_{2}}=\gamma_{\mathrm{S}_{1}}+\gamma_{\mathrm{S}_{2}}-\frac{4 \gamma_{\mathrm{S}_{1}}^{\mathrm{d}} \gamma_{\mathrm{S}_{2}}^{\mathrm{d}}}{\gamma_{\mathrm{S}_{1}}^{\mathrm{d}}+\gamma_{\mathrm{S}_{2}}^{\mathrm{d}}}-\frac{4 \gamma_{\mathrm{S}_{1}}^{\mathrm{p}} \gamma_{\mathrm{S}_{2}}^{\mathrm{p}}}{\gamma_{\mathrm{S}_{1}}^{\mathrm{p}}+\gamma_{\mathrm{S}_{2}}^{\mathrm{p}}}
$$

\subsubsection{Rotational rheometry}

The rheological properties of the pure PLA, pure PCL, and the blends were determined using an Anton Paar MCR 702 rotational rheometer equipped with a parallel plate geometry (diameter of $25 \mathrm{~mm}$ ). The samples were produced by FFF with the same printing parameters used for the tensile specimens. Several tests were performed on the samples at $180^{\circ} \mathrm{C}$ under a nitrogen atmosphere. Three tests were conducted for each protocol to ensure repeatability of the measures. First, the thermal stability of the pure materials was evaluated by dynamic time sweep tests at an angular frequency of $1 \mathrm{rad} / \mathrm{s}$ and a strain of $5 \%$. It was determined that none of the samples lost more than $5 \%$ of their initial rheological characteristics after $1 \mathrm{~h}$; hence, the results of these tests (not shown here) indicated the viability of the materials for a period of $1 \mathrm{~h}$ under a nitrogen atmosphere. Strain sweep tests were then conducted at a constant frequency of $1 \mathrm{~Hz}$ to determine the limit of the linear viscoelasticity region. Finally, frequency sweep tests were performed from 100 to $0.01 \mathrm{rad} / \mathrm{s}$ at a strain of $5 \%$ (this ensures that the materials remain in the linear viscoelasticity region).

\subsubsection{Porosity measurements}

The porosity $\varphi$ of the 3D-printed mono-material specimens used in this study was evaluated by comparing their apparent and bulk densities. The apparent density of the samples, $\rho_{\mathrm{a}}$, was calculated from the ratio of their mass $m$, measured with a scale (accuracy of $0.1 \mathrm{mg}$ ), and their apparent volume, $V_{\mathrm{e}}$, measured with a digital caliper. The bulk density, $\rho_{\mathrm{b}}$, of each material was measured with a helium pycnometer on specific printed samples with a similar thermal history compared to that of the dog-bone samples. Their geometry was perfectly suited for the pycnometer 
sample chamber and did not enable closed pores to be entrapped during manufacturing. Finally, the porosity was calculated using Equation (4):

$$
\varphi=1-\frac{\rho_{\mathrm{a}}}{\rho_{\mathrm{b}}}=1-\frac{m}{V_{\mathrm{e}} \rho_{\mathrm{b}}}
$$

\subsubsection{Mechanical characterization}

The mechanical characterization was conducted on a Z010/TH2S testing machine from Zwick Roell (Germany) in accordance with ISO 527-2 at $10 \mathrm{~mm} / \mathrm{min}$. A minimum of five tensile specimens were tested for each reported value. A load cell of $10 \mathrm{kN}$ with a precision of $0.1 \mathrm{~N}$ was used. For the assessment of Young's modulus (exclusively on mono-material and alternated bi-material specimens), the strain in the linear range was determined using a clip-on extensometer. Otherwise, the strain was evaluated based on crosshead displacement.

\section{Results and discussion}

\subsection{Differential scanning calorimetry}

The thermograms shown in Figure 3 were used to measure the melting peak temperature of the PCL phase in the blends, the melting enthalpy, and the peak temperature of the PLA phase in the blends, and the cold crystallization enthalpy and the peak temperature of the PLA phase. The degree of crystallinity of the PLA phase was calculated using Equation (1). All values are listed in Table 3.

The proximity of the glass transition temperature of PLA $\left(60^{\circ} \mathrm{C}\right)$ and the melting peak of PCL $\left(57^{\circ} \mathrm{C}\right)$

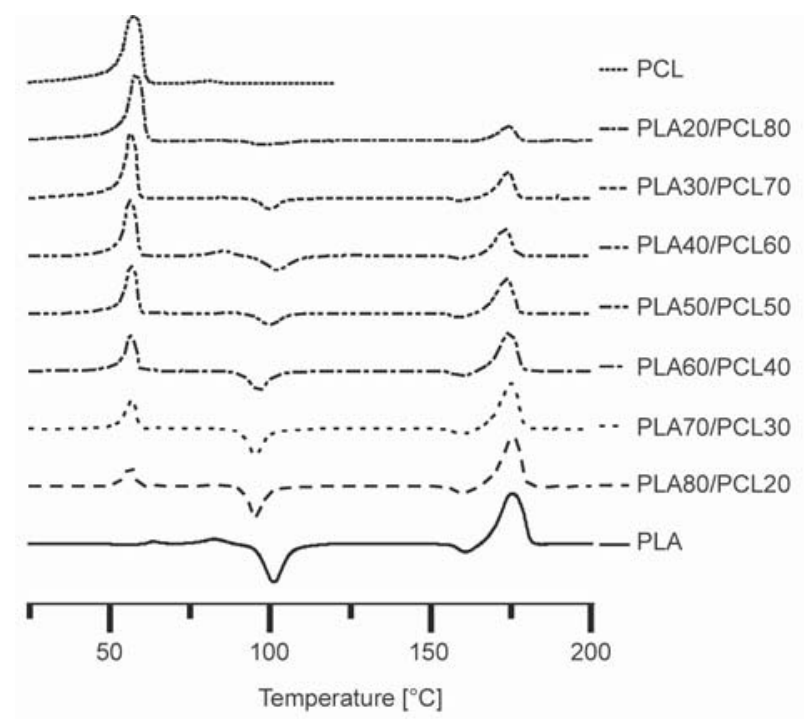

Figure 3. DSC thermograms of the PLA/PCL blends: endothermic heat flow during the second heating.
Table 3. Temperatures and enthalpies measured on the DSC thermograms and the associated degree of crystallinity for each blend.

\begin{tabular}{|c|c|c|c|c|c|c|}
\hline PLA/PCL & $\begin{array}{c}T_{\mathrm{m}} \\
(\mathbf{P C L}) \\
{\left[{ }^{\circ} \mathrm{C}\right]}\end{array}$ & $\begin{array}{c}H_{\mathrm{c}} \\
\text { (PLA) } \\
{[\mathbf{J} / \mathbf{g}]}\end{array}$ & $\begin{array}{c}T_{\mathrm{c}} \\
\text { (PLA) } \\
{\left[{ }^{\circ} \mathrm{C}\right]}\end{array}$ & $\begin{array}{c}H_{\mathrm{m}} \\
(\mathbf{P L A}) \\
{[\mathbf{J} / \mathrm{g}]}\end{array}$ & $\begin{array}{c}T_{\mathrm{m}} \\
\text { (PLA) } \\
{\left[{ }^{\circ} \mathrm{C}\right]}\end{array}$ & $\begin{array}{c}\chi_{c} \\
\text { (PLA) } \\
{[\%]}\end{array}$ \\
\hline $0 / 100$ & 57 & - & - & - & - & - \\
\hline $20 / 80$ & 57 & 4.8 & 97 & 8.8 & 173 & 22.2 \\
\hline $30 / 70$ & 57 & 8.4 & 100 & 14.5 & 175 & 22.2 \\
\hline $40 / 60$ & 56 & 7.7 & 102 & 15.4 & 173 & 21.2 \\
\hline $50 / 50$ & 57 & 10.9 & 100 & 21.0 & 174 & 22.3 \\
\hline $60 / 40$ & 57 & 15.7 & 97 & 24.7 & 176 & 16.4 \\
\hline $70 / 30$ & 57 & 17.3 & 95 & 27.5 & 175 & 15.9 \\
\hline $80 / 20$ & 56 & 20.6 & 95 & 31.8 & 175 & 15.4 \\
\hline $100 / 0$ & - & 22.0 & 101 & 25.2 & 176 & 3.7 \\
\hline
\end{tabular}

make it very difficult to distinguish between them in the thermograms of the blends. As a result, an endothermic peak due to both polymers was observed. Nevertheless, the temperature at which this peak occurs did not vary appreciably with the blending ratio. Similarly, the cold crystallization and melting peak temperatures of the PLA phase in the blends were very similar to those of pure PLA $\left(101\right.$ and $176^{\circ} \mathrm{C}$, respectively). This indicates that the blends form a highly immiscible system.

As displayed in Table 3, the degree of crystallinity of the PLA phase increased considerably when PCL was added to the blends. It is 5 to 6 times the ratio measured in pure PLA. These higher degrees of crystallinity are attributed to the presence of interfaces between the phases that act as nucleation regions for the PLA $[8,25]$.

\subsection{Rotational rheometry}

Rheological measurements were performed to obtain more information on the miscibility and the phase inversion of the blends. Figure 4 shows that the values of the complex viscosity $\eta^{*}$ for the PLA20/ PCL80, PLA30/PCL70, PLA40/PCL60, and PLA50/ PCL50 blends are similar to those of pure PCL at all frequencies. On the contrary, the values of PLA60/ PCL40, PLA70/PCL30, and PLA80/PCL20 have a singular rheological behavior. Their complex viscosity is in-between that of PLA and PCL at high frequencies, whereas it is much higher compared to that of PLA at low frequencies.

These observations are also valid for the loss modulus $G^{\prime \prime}$ (cf. Figure 5). It is well-known that the storage modulus $G^{\prime}$ is highly influenced by the morphology of the blend, especially at low frequencies (i.e. 


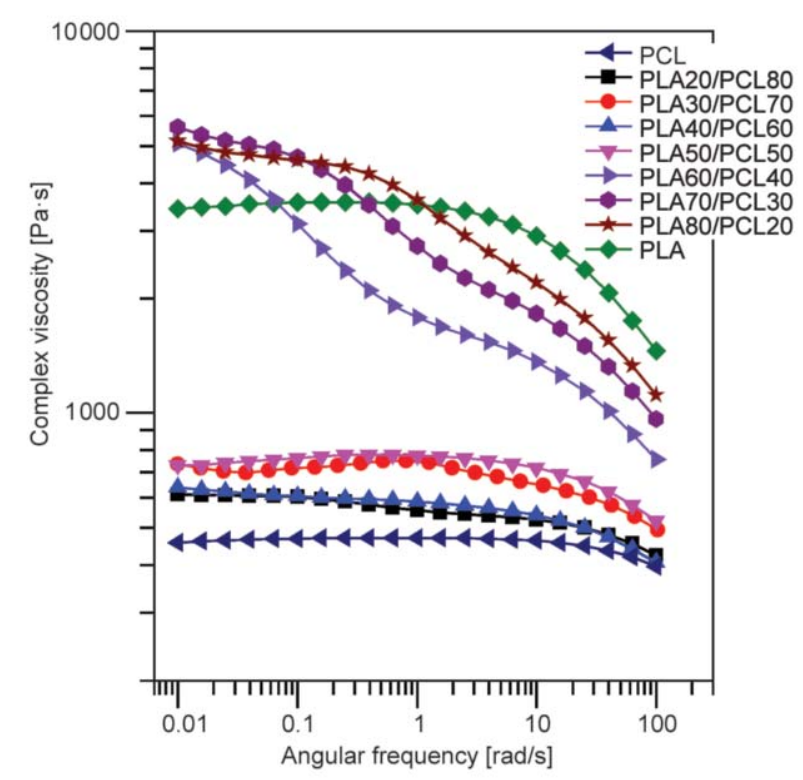

Figure 4. Complex viscosity $\left(\eta^{*}\right)$ of PLA, PCL and their blends measured at $180^{\circ} \mathrm{C}$.

$<1 \mathrm{rad} / \mathrm{s}$ ). At such frequencies, the $G^{\prime}$ values of the blends deviate from the characteristic slope of either pure PCL or pure PLA. In the cases of PLA20/ PCL80, PLA30/PCL70, PLA40/PCL60, and PLA50/ PCL50 that are immiscible binary polymer blends, this behavior is attributed to the PLA dispersed phase shape relaxation in the PCL matrix under oscillatory shear strain [8]. This shape relaxation that occurs at low frequencies induces an increase of the storage modulus, which is influenced by the interfacial behavior. Regarding the $G^{\prime}$ curve of PLA60/PCL40, PLA70/PCL30, and PLA80/PCL20, there is also a considerable deviation from the pure PLA curve

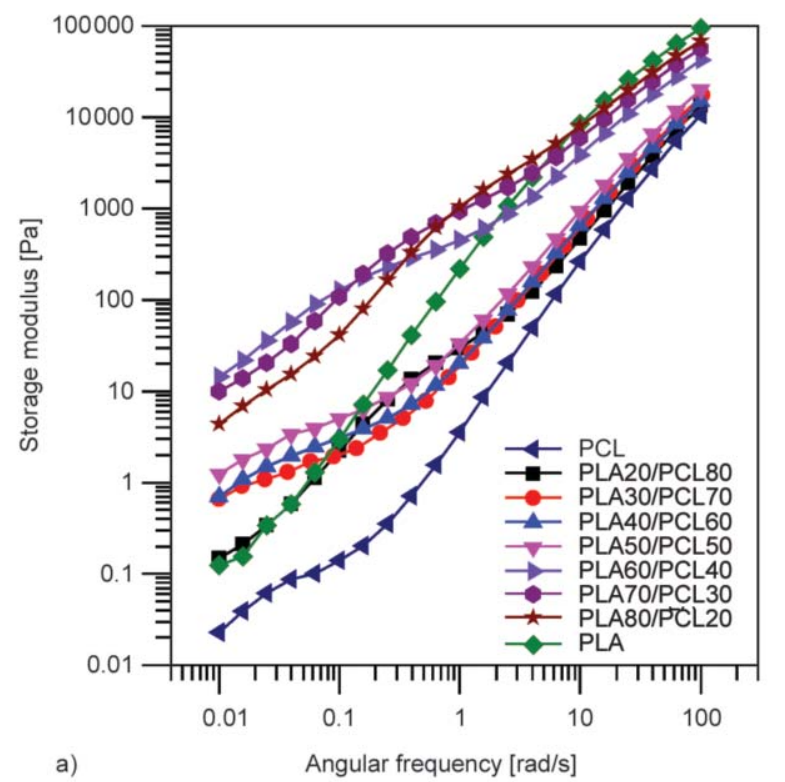

even at high frequencies. This can be attributed to the peculiar morphology of the PCL dispersed phase even after melting under rheological testing. As a result, it seems that from 0 to $50 \mathrm{wt} \%$ of PLA, PLA is the dispersed phase, and phase inversion occurs for PLA between 50 and $60 \mathrm{wt} \%$.

To gain more information about the microstructure of the blends in terms of their composition, it is possible to predict the phase inversion. There are several models for predicting the phase inversion of a blend. One of the simplest models was described by Paul and Barlow [26], which allows estimating the phase inversion point from the viscosity ratio. This model is also based on the assumption that the less viscous phase will have the greatest tendency to encapsulate the most viscous phase. Hence, the less viscous phase will have a high tendency to be the continuous phase. Many other empirical models based on the viscosity ratio have been developed to predict phase inversion, taking into account the mixing conditions and capillary instabilities (for example, Kitayama et al. [27]). Steinmann et al. [28] found a strong relation between phase inversion and the elasticity ratio evaluated at constant shear stress. Yet they proposed an equation on the basis of the viscosity ratio. Omonov et al. summarized these models [29]. They examined the dual-phase continuity of a PP/PS blend and proposed their own equation to predict phase inversion with respect to the viscosity ratio. In some cases, it was shown that the viscosity ratio did not accurately predict the point of phase inversion. Finally, Utracki [30] used an analogy related to low molecular weight

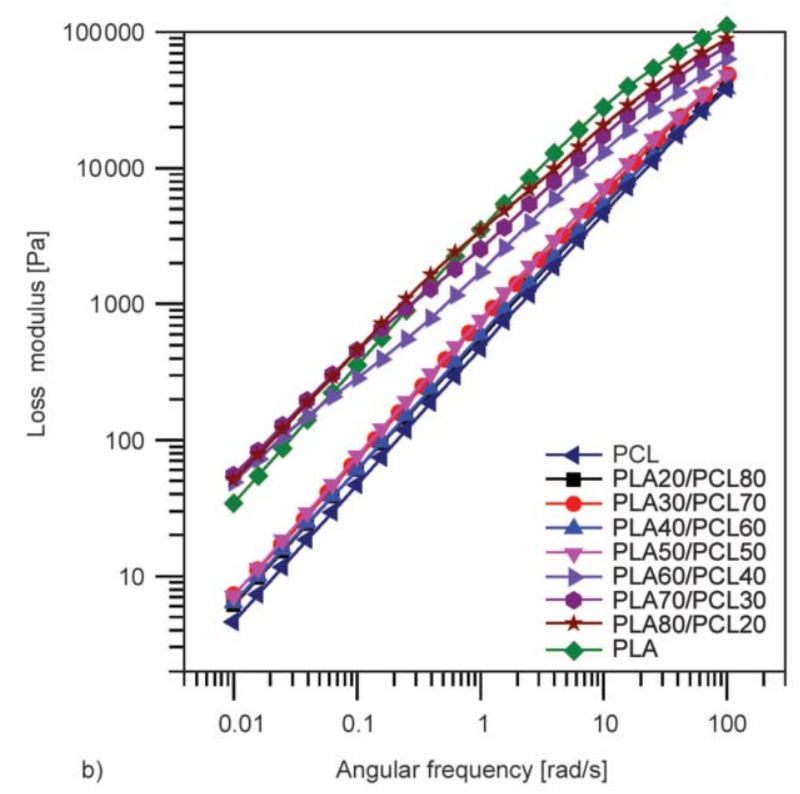

Figure 5. (a) Storage modulus $\left(G^{\prime}\right)$ and (b) loss modulus $\left(G^{\prime \prime}\right)$ of PLA, PCL and their blends measured at $180^{\circ} \mathrm{C}$. 
mixtures (i.e. emulsions) to take into account the increase in viscosity that results from adding one polymer to another. However, this model introduces two variables: the intrinsic viscosity $[\eta]$ and the maximum packing volume fraction $\phi_{\mathrm{m}}$. Nevertheless, they can be easily estimated by selecting typical values found in the literature $\left([\eta] \cdot \phi_{\mathrm{m}}=1.92\right)[31]$.

In our case (based on experimental data gathered in Table 4), using the model of Paul and Barlow, given that the PLA is much more viscous than the PCL, it is expected that phase inversion takes place at $80 \mathrm{wt} \%$ of PLA (cf. Table 5). This prediction is far from the interpretation based on the experimental results because the viscosity ratio in the present case is not close to one. The Kitayama or Steinman model leads to a more reasonable point of phase inversion as the Kitayama model predicts phase inversion at $64 \mathrm{wt} \%$ of PLA and the Steinmann model at $57 \mathrm{wt} \%$. Using the Omonov model, phase inversion could occur below $50 \mathrm{wt} \%$. This value is not aberrant but nevertheless contradicts the rheological tests. Finally, Utracki predicts a phase inversion at $59 \mathrm{wt} \%$. In summary, the models of Steinmann et al. and Utracki provide the most consistent results for experimental data. This suggests that phase relaxation and/or increase in viscosity plays a role in phase inversion of PLA/PCL blends.

Table 4. Data used to calculate the weight fraction of PCL at phase inversion.

\begin{tabular}{|c|c|c|}
\hline Material & PCL & PLA \\
\hline Specific gravity, $\rho$ & 1.14 & 1.25 \\
\hline Complex viscosity, $\eta(\dot{\gamma}=100 \mathrm{rad} / \mathrm{s})[\mathrm{Pa} \cdot \mathrm{s}]$ & 396 & 1456 \\
\hline Elastic modulus, $G^{\prime}(\dot{\gamma}=100 \mathrm{rad} / \mathrm{s}) \quad[\mathrm{Pa}]$ & 10486 & 94517 \\
\hline Damping factor, $\tan \delta(\dot{\gamma}=100 \mathrm{rad} / \mathrm{s})[-]$ & 3.64 & 1.17 \\
\hline
\end{tabular}

\subsection{Interfacial tension and surface energies}

Table 6 shows values for the contact angles obtained for PLA and PCL with the three test liquids. Using these values, the Owens and Wendt plots in Figure 6 were obtained for PLA and PCL. The high $R^{2}$ value $(>0.95)$ indicates that there is good agreement between the experimental data and the Owens and Wendt linear fit for both materials. This allows the dispersive and polar components of the surface energies to be determined, as shown in Table 7.

The proximity of the surface energy values and the low variation of the collected data suggest that the pure materials have very similar interactions with the solvents, although PLA is more hydrophilic. It also

Table 6. Contact angles (in degrees) of PLA and PCL with the test liquids.

\begin{tabular}{|c|c|c|c|}
\hline Test liquids & Water & Diiodomethane & Ethylene glycol \\
\hline PLA & $70.6 \pm 1.7$ & $40.2 \pm 1.1$ & $42.4 \pm 0.7$ \\
\hline PCL & $80.3 \pm 1.1$ & $37.0 \pm 1.2$ & $46.7 \pm 0.5$ \\
\hline
\end{tabular}

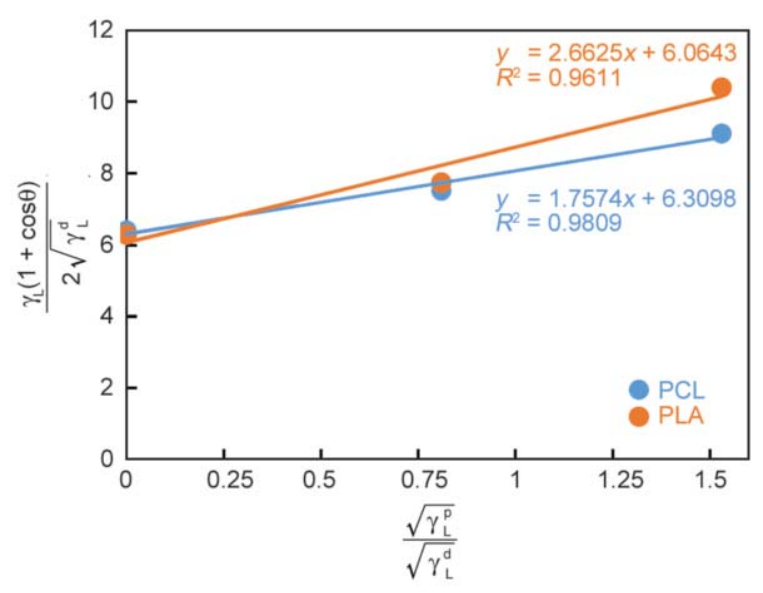

Figure 6. Owens and Wendt plots for PLA and PCL.

Table 5. Phase inversion models for PLA/PCL blends.

\begin{tabular}{|c|c|c|c|}
\hline Author & Equation & $\begin{array}{c}\phi_{\text {PLA }} \\
{[\text { Vol\%] }}\end{array}$ & $\begin{array}{c}\phi_{\text {PLA }} \\
{[\mathbf{w t} \%]}\end{array}$ \\
\hline Paul and Barlow & $\frac{\phi_{\mathrm{PCL}}}{\phi_{\mathrm{PLA}}}=\frac{\eta_{\mathrm{PCL}}}{\eta_{\mathrm{PLA}}}$ & 79 & 80 \\
\hline Kitayama et al. & $\frac{\phi_{\mathrm{PCL}}}{\phi_{\mathrm{PLA}}}=0.887\left(\frac{\eta_{\mathrm{PCL}}}{\eta_{\mathrm{PLA}}}\right)^{0.29}$ & 62 & 64 \\
\hline Steinmann et al. & $\phi_{\mathrm{PLA}}=-0.12 \log \left(\frac{\eta_{\mathrm{PCL}}}{\eta_{\mathrm{PLA}}}\right)+0.48$ & 55 & 57 \\
\hline Omonov et al. & $\frac{\phi_{\mathrm{PCL}}}{\phi_{\mathrm{PLA}}}=1.59\left(\frac{\eta_{\mathrm{PCL}}}{\eta_{\mathrm{PLA}}}\right)^{0.19}$ & 45 & 47 \\
\hline Utracki & $\frac{\eta_{\mathrm{PCL}}}{\eta_{\mathrm{PLA}}}=\left(\frac{\phi_{\mathrm{m}}-\phi_{\mathrm{PLA}}}{\phi_{\mathrm{m}}-\phi_{\mathrm{PCL}}}\right)^{[\eta] \phi_{\mathrm{m}}}$ & 57 & 59 \\
\hline
\end{tabular}


Table 7. Surface energies of PLA and PCL.

\begin{tabular}{|c|c|c|c|}
\hline Components & $\begin{array}{c}\boldsymbol{\gamma}_{\mathbf{S}} \\
{[\mathbf{m N} / \mathbf{m}]}\end{array}$ & $\begin{array}{c}\boldsymbol{\gamma}_{\mathbf{S}}^{\mathbf{p}} \\
{[\mathbf{m N} / \mathbf{m}]}\end{array}$ & $\begin{array}{c}\boldsymbol{\gamma}_{\mathbf{S}}^{\mathbf{d}} \\
{[\mathbf{m N} / \mathbf{m}]}\end{array}$ \\
\hline PLA & $43.9 \pm 0.7$ & $7.1 \pm 0.5$ & $36.8 \pm 0.2$ \\
\hline PCL & $42.9 \pm 0.5$ & $3.1 \pm 0.2$ & $39.8 \pm 0.3$ \\
\hline
\end{tabular}

suggests that the interfaces between the two phases in the blends will exhibit good adhesion properties.

The interfacial tension between the PLA and PCL phases determined using Wu's method was $1.69 \pm 0.17 \mathrm{mN} \cdot \mathrm{m}^{-1}$. This value is very similar to those obtained in previous works related to PLA/PCL blends using the same methodology, i.e. $1.206 \mathrm{mN} \cdot \mathrm{m}^{-1}$

PLA/PCL ratio

Transversal plane

Longitudinal plane
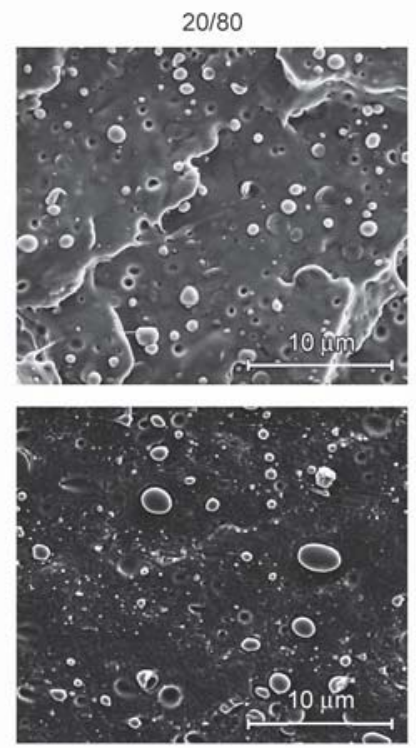

$60 / 40$
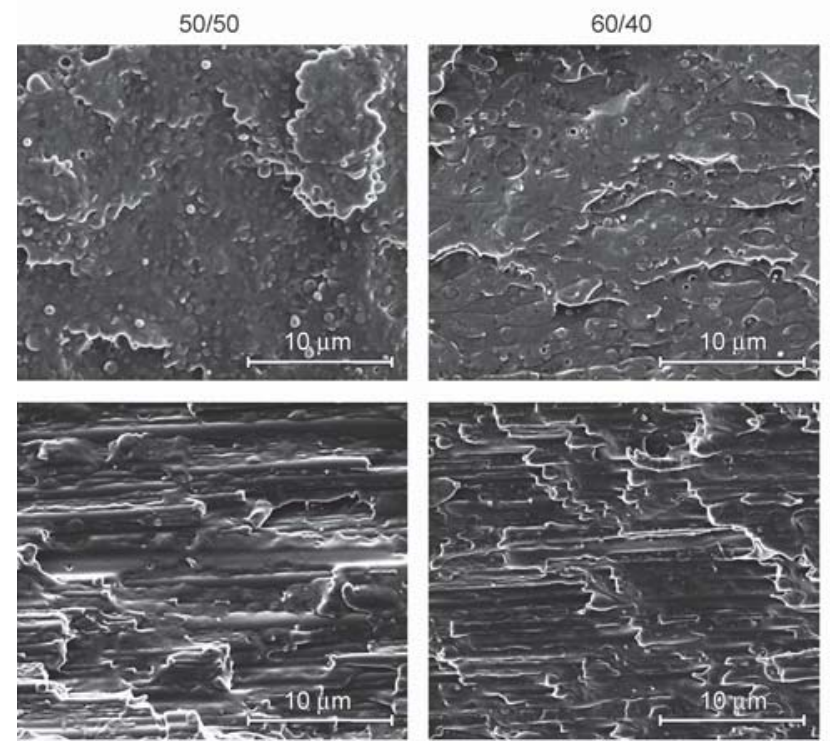

[8], $0.9 \mathrm{mN} \cdot \mathrm{m}^{-1}$ [9], and $1.55 \mathrm{mN} \cdot \mathrm{m}^{-1}$ [11]. These values tend to be correlated to the size of the particles in the dispersed phase reported in the literature; the lower the interfacial tension, the smaller the diameter of the droplets [11]. The difference between the value obtained and the values calculated in previous works is most likely due to the different processing conditions and the different viscosity ratios between the polymers.

\subsection{Microstructure}

SEM micrographs of cryo-fractured $2.85 \mathrm{~mm}$ calibrated filaments are displayed in Figure 7. For each
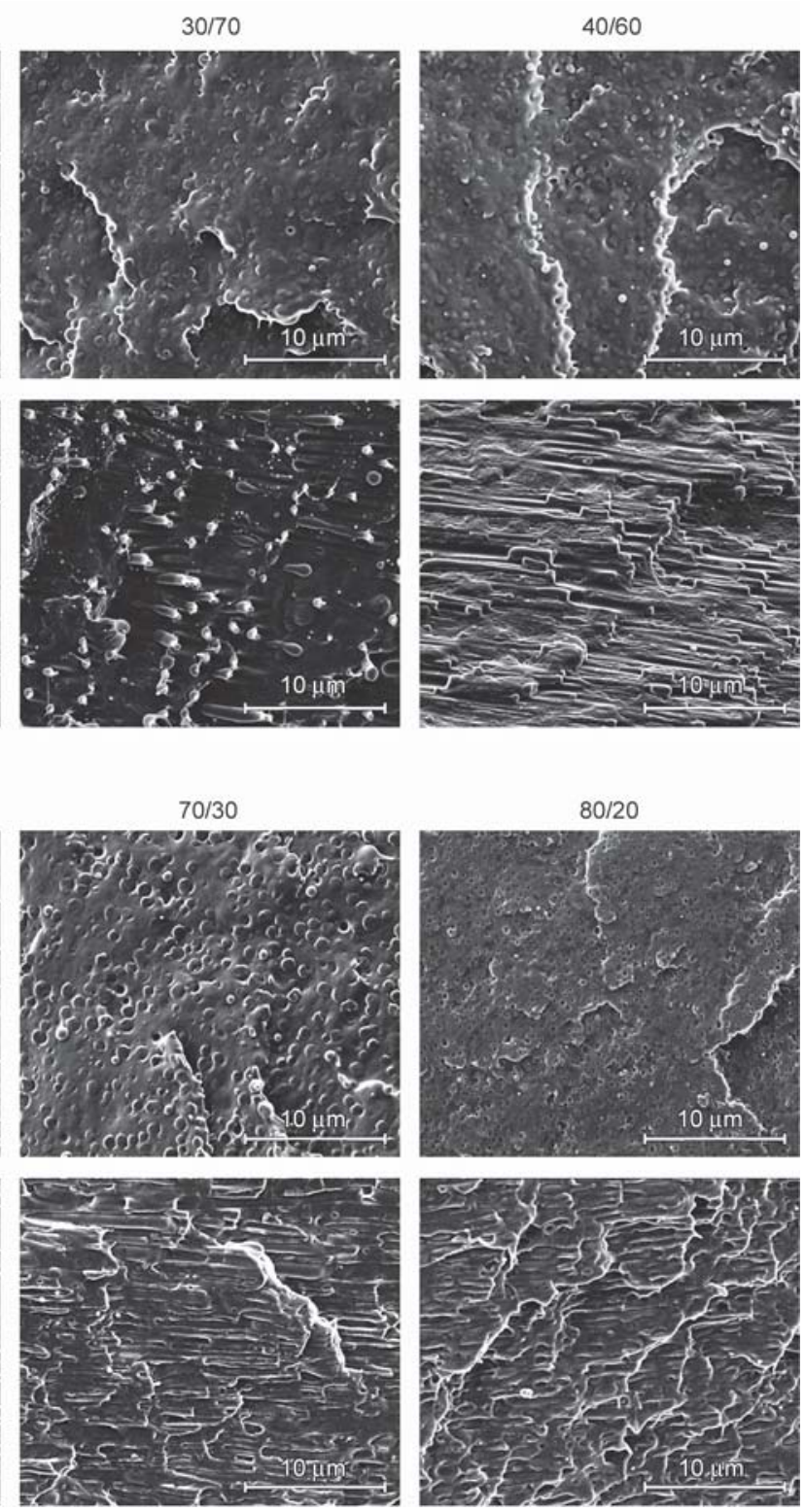

Figure 7. SEM observations of cryo-fractured $2.85 \mathrm{~mm}$ calibrated filaments of various blend ratios depending on the plane of fracture relative to the filament axis. 
blending ratio, filaments were fractured along a transversal plane and a longitudinal plane to better estimate the influence of the process.

The images show that the samples exhibit biphasic compositions regardless of the blend ratios. The visible interface between the two phases is indicative of the high immiscibility of this system, confirming the observation of the DSC thermograms.

For the PLA20/PCL80 blends, PLA phases appear as droplets that are efficiently dispersed into the PCL matrix. Their diameters range from 0.1 to $2 \mu \mathrm{m}$ and are small compared to those observed in previous works $[6,9]$. The increase in the PLA content in PLA30/PCL70 does not seem to cause a significant variation in the size of PLA droplets. However, the longitudinal cross-section of PLA30/PCL70 suggests fibrillation of the PLA dispersed phase. From 30PLA/70PCL to 50PLA/50PCL the aspect ratio of the PLA dispersed phase increased with the PLA content. Increasing the PLA content from 50PLA/ 50PCL seems to lead to a phase inversion of the transversal plane with a co-continuous morphology at $60 \mathrm{PLA} / 40 \mathrm{PCL}$ reported in the literature $[9,11]$. Finally, the longitudinal cross-sections of 70PLA/ 30PCL and 80PLA/20PCL exhibit a fibrillar microstructure with fibrils of dozens of micrometers. The PLA80/PCL20 blend does not exhibit the same microstructure as that of PLA20/PCL80. Instead, the PCL phase is highly stretched and forms thin filaments (as shown in the longitudinal cross-section) of a few hundred nanometers in diameter (as shown in the transversal cross-section).

The small PCL filament diameter in PLA80/PCL20 is attributed to the low viscosity of PCL compared to the viscosity of PLA, which makes them prone to stretching during extrusion. Conversely, for the same reason, PLA inclusions are barely stretched in PLA20/
PCL80. Moreover, these different behaviors are amplified by the lower processing temperature (cf. 2.1) of blends with PLA inclusions and the higher processing temperature of blends with PCL inclusions.

Figure 8 displays the SEM observations of PLA phases in PLA40/PCL60, PLA50/PCL50, and PLA60/ PCL40 blend filaments that were cryo-fractured in a longitudinal plane and etched with tetrahydrofuran (THF) to dissolve the PCL phase on the surface of the samples. These images reveal a fibrillar organization of the PLA phase. Due to the processing method for the filaments, this fibrillar morphology is oriented following the axis of the filament. During FFF, this morphology could potentially increase anisotropy, provided that the printing process does not alter the filament microstructure. This is unlikely given that extrusion through a FFF nozzle tends to promote orientation in the deposed filament axis as well. It is thus difficult to determine a possible dual-phase continuity for the $40 / 60,50 / 50$, and $60 / 40$ samples.

Atomic force microscopy was performed to better assess the morphology of the PLA60/PCL40 filament. Figure 9 shows topography and phase AFM images of filaments in the transversal and longitudinal planes. From the topography data, it can be observed that surfaces prepared with the ultra-cryo-microtome have a very low roughness. By analyzing the phase coupled to the topography, a clear contrast can be observed between the softer material, PCL, with the higher phase shift, and the stiffer one, PLA, with the lower phase shift. These micrographs confirmed the immiscibility of the polymers. Phase micrographs were segmented using a manual threshold to assess the blend ratio. In the transversal plane, the PLA volume fraction was determined to be $57 \mathrm{vol} \%$ (i.e. $59 \mathrm{wt} \%$ ) while in the longitudinal plane, it was determined to be $55 \mathrm{vol} \%$ (i.e. $57 \mathrm{wt} \%$ ). Considering
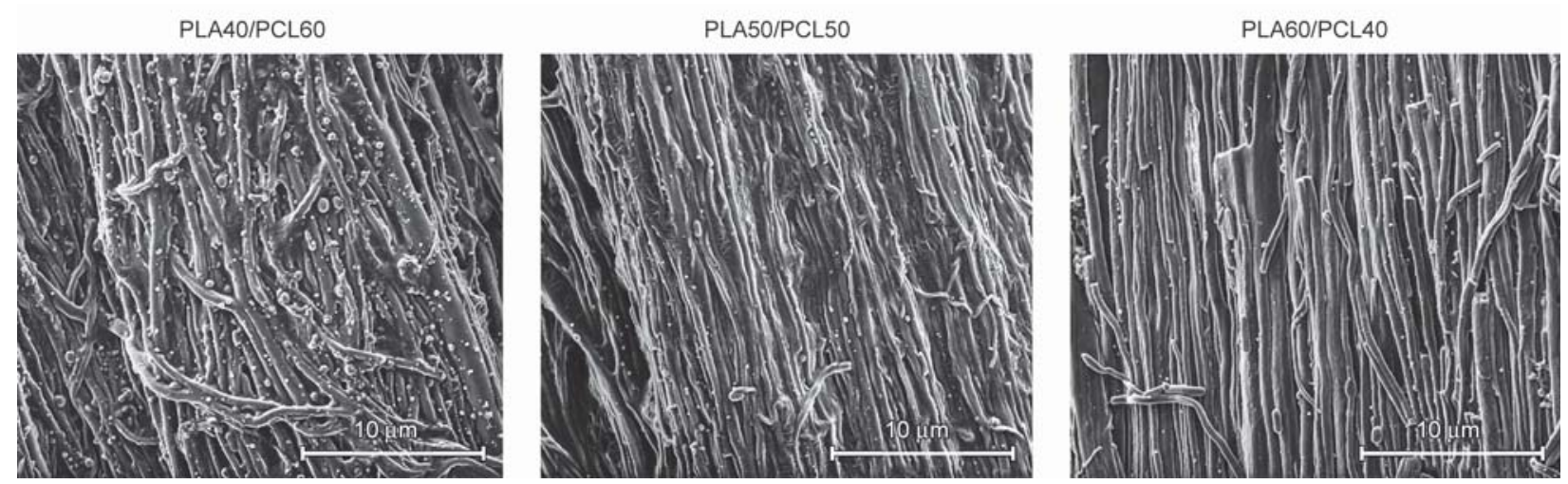

Figure 8. SEM observations of $2.85 \mathrm{~mm}$ calibrated filament of various blend ratios that were cryo-fractured in a longitudinal plane and etched with THF. 

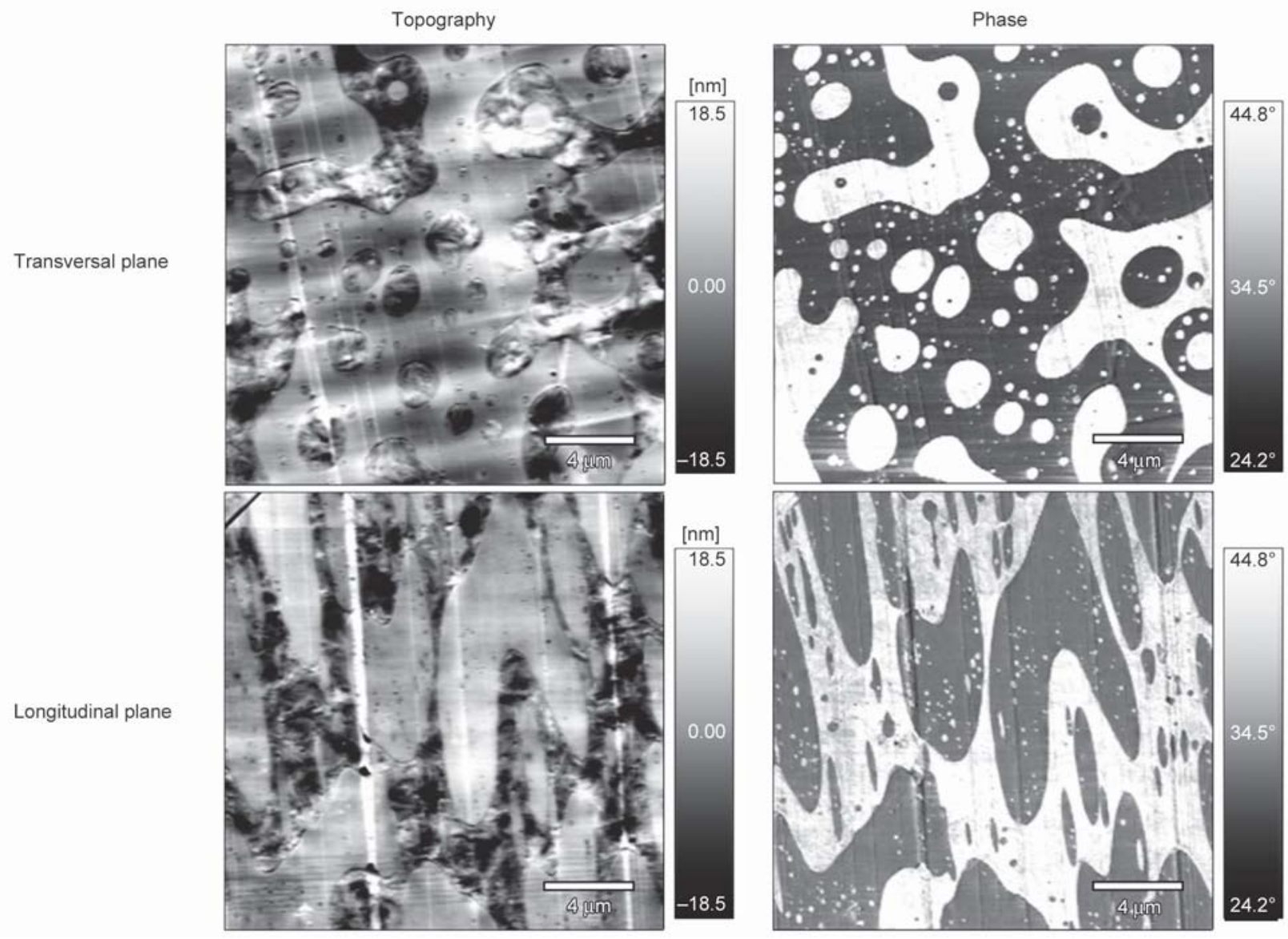

Figure 9. AFM topography and phase imaging of a PLA60/PCL40 calibrated filament in the transversal and longitudinal planes.

that the small size of the scanned areas is not representative of the average blend ratio, these values are fairly close to the targeted blend ratio. In addition, phase imaging in the longitudinal and transversal planes revealed different microstructures, confirming the fibrillar organization observed via SEM imaging. In addition, in the transversal plane, the matrix consists of PLA, while in the longitudinal plane, it consists of PCL. This proves that the PLA60/ PCL40 blend presents a co-continuous morphology

\subsection{The porosity of printed specimens}

Specimens from the FFF technology were characterized to evaluate whether a relatively high degree of crystallinity, medium interfacial tension, and fibrillar morphology of the blends could be beneficial to the mechanical properties. It is well-known that FFF technology can generate high porosities that are formed in between the deposited filaments.

Firstly, the bulk density was evaluated with a helium pycnometer for the different blends. Figure 10 shows that the bulk density of PLA/PCL blends increases linearly with the PLA content. This implies that the bulk density of the blends follows the rule of mixture. Finally, the porosity of the printed samples was determined to evaluate their quality. Table 8 shows the values of their bulk density, apparent density, and porosity according to the blend ratio. All porosities are typical for FFF (i.e. a low percentage value) [32] and relatively low.

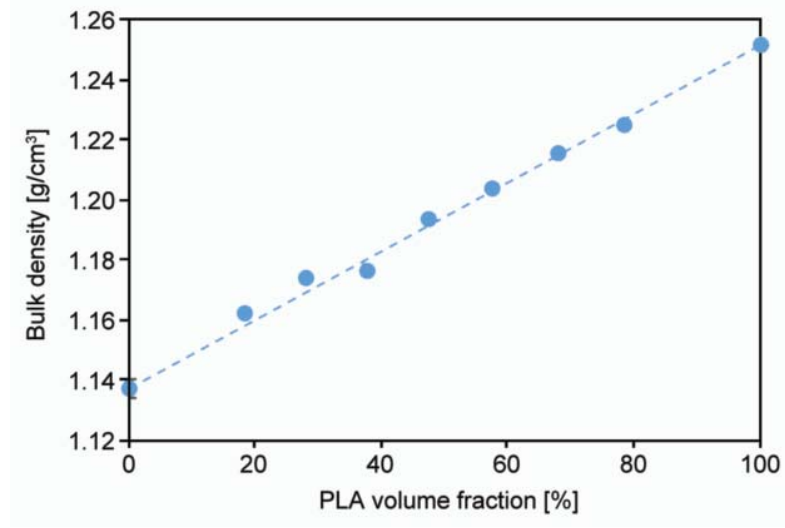

Figure 10. Bulk density of PLA, PCL and their blends as a function of PLA weight content. 
Table 8. Bulk density, apparent density, and porosity of printed specimens.

\begin{tabular}{|c|c|c|c|}
\hline PLA/PCL & $\begin{array}{c}\mathbf{\rho}_{\mathbf{b}} \\
{\left[\mathbf{g} / \mathbf{c m}^{3}\right]}\end{array}$ & $\begin{array}{c}\mathbf{\rho}_{\mathbf{a}} \\
{\left[\mathbf{g} / \mathbf{c m}^{3}\right]}\end{array}$ & $\begin{array}{c}\boldsymbol{\varphi} \\
{[\mathbf{\%}]}\end{array}$ \\
\hline $0 / 100$ & $1.1372 \pm 0.003$ & $1.069 \pm 0.007$ & $6.0 \pm 2.8$ \\
\hline $30 / 70$ & $1.1742 \pm 0.001$ & $1.146 \pm 0.003$ & $2.4 \pm 0.8$ \\
\hline $40 / 60$ & $1.1760 \pm 0.001$ & $1.138 \pm 0.003$ & $3.2 \pm 0.8$ \\
\hline $70 / 30$ & $1.2159 \pm 0.001$ & $1.160 \pm 0.006$ & $4.6 \pm 1.0$ \\
\hline $80 / 20$ & $1.2247 \pm 0.001$ & $1.179 \pm 0.006$ & $3.7 \pm 1.1$ \\
\hline $100 / 0$ & $1.2512 \pm 0.001$ & $1.217 \pm 0.003$ & $2.8 \pm 0.7$ \\
\hline
\end{tabular}

In pure PLA, pores are barely visible to the naked eye. They are mainly located at the boundary between outlines and infill. On the contrary, the porosity of PCL is significant. This result may be explained by the lower printing temperature of PCL (cf. Table 1), which reduces its ability to flow and fill the voids properly.

\subsection{Mechanical behavior}

\subsubsection{Mono-material specimens}

The tensile mechanical behavior of printed monomaterial specimens is plotted in Figure 11. It exhibits two distinct behaviors: a ductile behavior for low PLA/PCL ratios whereby the strain at break decreases as the PLA content increases without significantly changing the strength. In addition, a brittle behavior is observed for high PLA/PCL ratios, whereby the strength decreases as the PCL content increases without significantly changing the strain at break. The transition from the brittle to ductile behavior is abrupt. This suggests that blend behavior is mainly driven by the majority phase. The change in behavior occurs approximately at a ratio of 40/60 of PLA/PCL.

Young's moduli of the different structures are compared as a function of the PLA/PCL ratio in Figure 12.

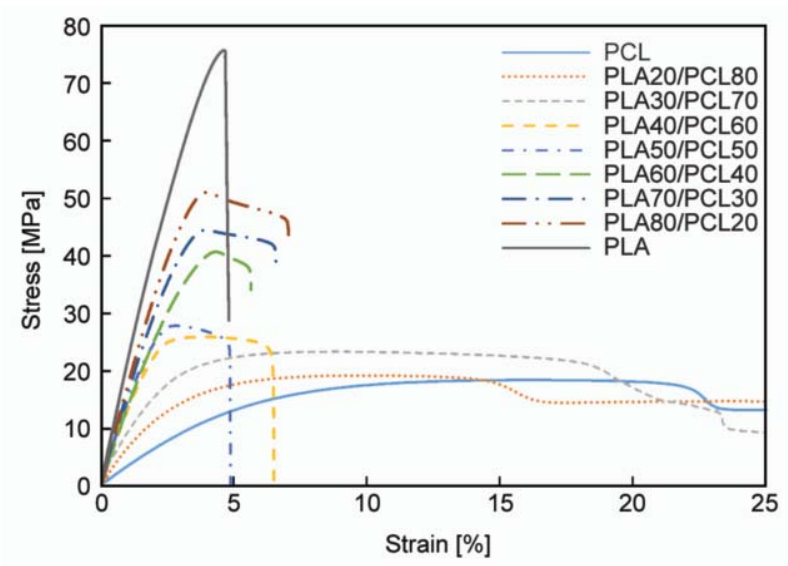

Figure 11. Tensile stress-strain behavior of printed monomaterial specimens.
For mono-materials, Young's modulus increases monotonously from approximately $0.5 \mathrm{GPa}$ to almost $4.0 \mathrm{GPa}$ as the blend ratio increases. However, a strong increase of the modulus is observed between PLA40/PCL60 and PLA50/PCL50 for injected samples and PLA50/PCL50 and PLA60/PCL40 for printed samples. This suggests that a phase inversion occurs between these two compositions. The lower blend ratio at which the phase inversion occurs for the injected samples might be attributed to the higher shear rate experienced during this process.

The influence of the process (injection or FFF) on the modulus is surprisingly very limited. Indeed, the modulus was expected to be significantly lower for the printed specimens due to their inherent porosity (i.e. smaller resistive section, presence of defects) [33]. On the contrary, the printed samples of PLA30/ PCL70 and PLA40/PCL60 exhibited a significantly higher modulus than their injected counterparts. These unusual results for FFF printed specimens are attributed to a combination of the low porosity (cf. Table 8) and the advantageous cooling kinetics that potentially increased the crystallinity.

Different models were used to simulate Young's modulus of the blends. All of them assume cohesive phases. Initially, Reuss [34] and Voigt [35] bounds were plotted. These bounds represent the lower and upper values that the blend modulus can assume for a given ratio, respectively. All experimental values were well within these limits.

The Mori-Tanaka model [36] is often used to predict Young's modulus of immiscible binary polymer blends $[13,37]$. It is based on the hypothesis of homogeneously distributed ellipsoidal droplets in a majority phase (i.e. matrix). This model was compared

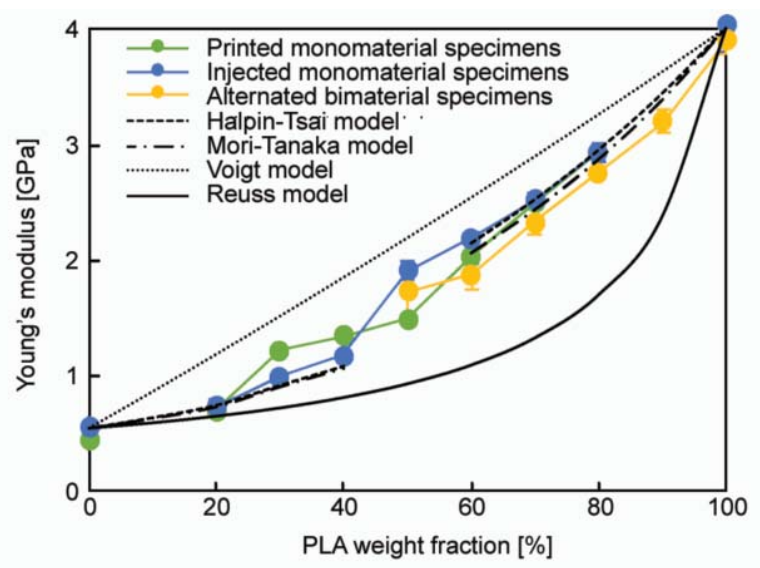

Figure 12. Young's modulus of different specimen types as a function of the total PLA weight fraction in the sample. 
to the Halpin-Tsai model [38] that predicts Young's modulus of composites reinforced with various inclusion geometries ranging from spheres to fibershaped inclusions. In this case, both these models were used, assuming a shape factor (length to width ratio) for inclusions (ellipsoid for Mori-Tanaka and cylinders for Halpin-Tsai) of 1 and 25 respectively, for PLA contents below and above $25 \mathrm{wt} \%$, to be approximately representative of the SEM observations. Inclusions are considered to be perfectly aligned with the filament deposition direction [39]. Based on the laminate theory, the simulation considers the alternating $\pm 45^{\circ}$ deposition orientation (relative to the main direction of the specimens) of the printed filament from one layer to another. Given that the phase inversion of the blends for PLA/PCL ratios approaches 50/50, these models are not suitable in these cases. Table 9 shows Young's modulus values measured on printed and injected specimens and for blend values calculated using the Halpin-Tsai and Mori-Tanaka models. Both models predict very similar moduli irrespective of the blend ratio. Their values are also similar to the experimental values for the injectionmolded samples except for PLA30/PCL70 and

Table 9. Young's modulus for printed and injected blends, and for the Halpin-Tsai and Mori-Tanaka models.

\begin{tabular}{|c|c|c|c|c|}
\hline PLA/PCL & $\begin{array}{c}\boldsymbol{E}_{\text {printed }} \\
{[\mathbf{G P a}]}\end{array}$ & $\begin{array}{c}\boldsymbol{E}_{\text {injected }} \\
{[\mathbf{G P a}]}\end{array}$ & $\begin{array}{c}\boldsymbol{E}_{\text {Halpin-Tsai }} \\
{[\mathbf{G P a}]}\end{array}$ & $\begin{array}{c}\boldsymbol{E}_{\text {Mori-Tanaka }} \\
{[\mathbf{G P a}]}\end{array}$ \\
\hline $0 / 100$ & $0.46 \pm 0.02$ & $0.56 \pm 0.05$ & 0.55 & 0.55 \\
\hline $20 / 80$ & $0.70 \pm 0.01$ & $0.74 \pm 0.05$ & 0.75 & 0.73 \\
\hline $30 / 70$ & $1.22 \pm 0.02$ & $0.99 \pm 0.02$ & 0.92 & 0.91 \\
\hline $40 / 60$ & $1.35 \pm 0.01$ & $1.18 \pm 0.04$ & 1.09 & 1.07 \\
\hline $60 / 40$ & $2.03 \pm 0.07$ & $2.19 \pm 0.06$ & 2.15 & 2.06 \\
\hline $70 / 30$ & $2.50 \pm 0.06$ & $2.52 \pm 0.06$ & 2.52 & 2.43 \\
\hline $80 / 20$ & $2.94 \pm 0.08$ & $2.94 \pm 0.08$ & 2.95 & 2.87 \\
\hline $100 / 0$ & $3.91 \pm 0.13$ & $4.04 \pm 0.23$ & 4.00 & 4.00 \\
\hline
\end{tabular}

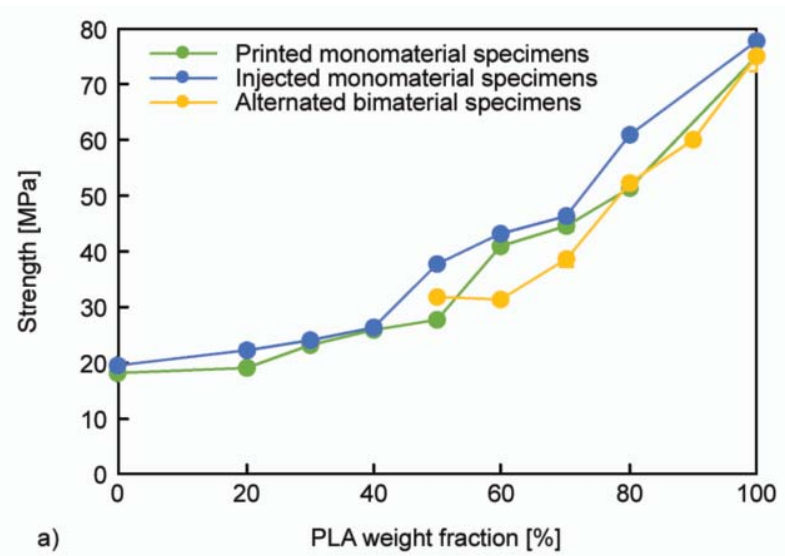

PLA40/PCL60, for which the models underestimate the experimental values. This surprising result is attributed to the significant crystallinity of the specimens (cf. Table 3), which is expected to increase their stiffness.

The evolution of the strength, according to the PLA/ PCL ratio, is plotted in Figure 13. For mono-materials, it was fairly similar to the evolution of Young's modulus; however, the influence of the process is more pronounced. Indeed, the values for the printed specimens are slightly lower than those of the injection-molded specimens. However, they remain very high, demonstrating the interest of such a blend for FFF.

As shown in Figure 13, the evolution of the strain at strength as a function of the PLA/PCL ratio is not progressive. The ductility decreases with the increasing PLA content until 50 and $40 \mathrm{wt} \%$ of PLA is present in the blend for injection-molded and printed monomaterial specimens, respectively. Beyond this ratio, the decrease of the PCL amount does not induce any more decrease of the strain at strength, which remains close to that of pure PLA (i.e. 4\%). When PCL is the majority phase (i.e. below $50 \mathrm{wt} \%$ of PLA), the ductility is significantly better for the injectionmolded samples than the printed samples. Otherwise it is almost identical.

\subsubsection{Alternated bi-material specimens}

To evaluate the quality of interfaces between PLA and its blends, the elastic and failure behavior of alternated bi-material specimens (cf. Figure 1) was assessed and compared to the printed mono-material specimens. Given that the alternating pattern is halfmade of PLA layers and blend layers, the total amount of PLA ranges from 50 to $100 \mathrm{wt} \%$.

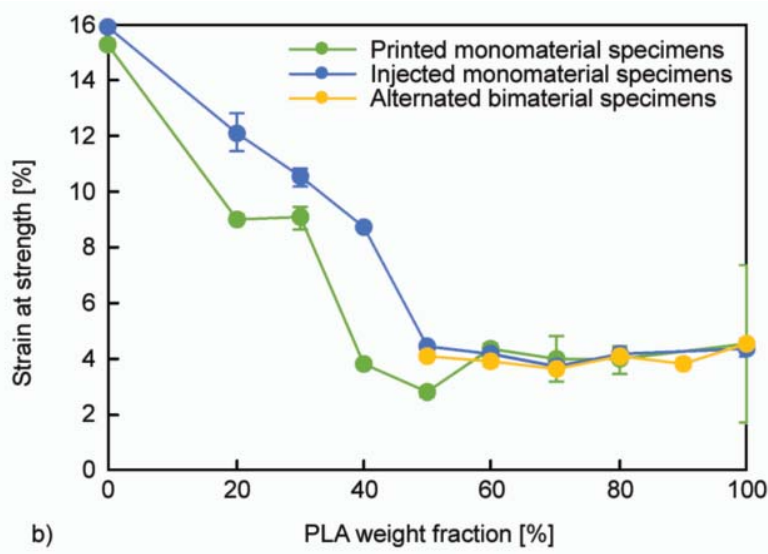

Figure 13. Strength and strain at break of different specimen types as a function of the total PLA weight fraction in the sample. 
Figure 12 shows that alternating layers of PLA and blends result in a similar but slightly lower stiffness compared to the case in which PCL is evenly distributed in all the layers.

Figure 13 shows that the strength is also fairly similar to that of the printed mono-materials, except for PLA total weight fractions of 60 and $70 \mathrm{wt} \%$, for which the mono-material specimens are more resistant. Given that the strain is identical in all layers during the tensile test, it is supposed that the stress in the blend layers is much lower than that in the PLA (cf. Figure 1). Hence approaching the strain at break, the stress in the PLA layers is higher than that in the blend layers of the mono-material samples, resulting in their early failure.

Concerning the strain at strength, the values are almost identical to that of the injection-molded and printed mono-materials (cf. Figure 13). This suggests that the distribution of PCL into PLA does not significantly alter the ductility of the blend, and the brittle behavior continues to be driven by the majority PLA phase.

As a result, the mechanical properties of the alternating pattern are not better than those of the blends with the same total amount of PLA. Nevertheless, they are still much higher than those of their constituent blend. Consequently, the alternating pattern fulfills its goals, that is, increasing the PLA/blend interface area and the creation of a gradient of properties between PLA and the blend.

\subsubsection{Bi-material gradient specimens}

Finally, to evaluate the potential benefit of using alternated layers as a means of connecting PLA to its blends, the tensile strength of bi-material gradient specimens (cf. Figure 2) was evaluated. Firstly, it was noted that during the tensile tests, the failure of the bi-material gradient specimens always occurred at the cross-section separating the alternated zone from the end of the sample made of the blend (cf. crosssection plane and dashed line in Figure 2). This implies that the strength of these specimens is lower than that of all three regions considered separately (i.e. the PLA, the blend, and the alternated zone). The strength values displayed in Figure 14 are consistent with this observation. Indeed, irrespective of the blend ratio, the strength of the bi-material gradient specimens is lower than that of the printed mono-material specimens, and therefore, than that of alternated bimaterial specimens.

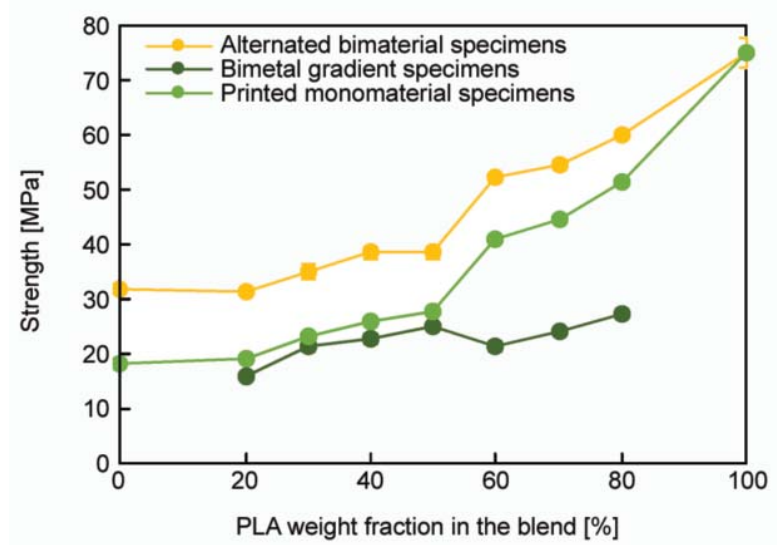

Figure 14. Strength of bi-material gradient and alternated bimaterial specimens as a function of the PLA weight fraction in the blend.

In the cross-section where failures occurred, the interface between PLA and the blend is orthogonal to the loading direction. Consequently, these layers could not provide efficient strength. During loading, the resistive section area decreased quickly, and stresses were transferred to the other layers. The high-stress concentration on these blend layers led to the rupture of the specimen in this specific section. As a result, the connection between the alternated region and the blend was the weak spot for this kind of structure.

Similarly to both the mono-material and the alternated bi-material specimens, the strength of the bi-material gradient specimens increased with the PLA fraction in the blend, albeit slightly. From 20 to $50 \mathrm{wt} \%$ of PLA, their strength is close to that of the blend, indicating a good interface quality between the blend and the PLA. However, above the phase inversion (cf. 3.2), instead of increasing sharply, the strength remains nearly constant at approximately half of that of the blend. This suggests that the PLA/blend interface in the cross-section did not contribute to the strength of the sample. This result is very surprising, considering that the PLA/blend adherence should increase with PLA content. It is believed that the higher viscosity of PLA limited diffusion and its ability to fill voids between filaments, for which the PCL is highly prone [14]. When PCL is not continuous in the blend, this results in a smaller and weaker contact area between the blend and the PLA. Moreover, the significant duration between the deposition of two adjacent filaments of blend and PLA exacerbates this behavior, which may result in a similar situation to a dry joint in the field of welding if PLA is continuous. 


\section{Conclusions}

This study investigated the use of poly(lactic acid)/ poly ( $\varepsilon$-caprolactone) blends to tailor the mechanical properties of parts manufactured via fused filament fabrication. It was shown that these blends are totally immiscible, although they have very similar surface energies. This is the reason for the good dispersion and size distribution of inclusions inside the matrix. SEM micrographs revealed that during extrusion of calibrated filaments, both phases tend to adopt a fibrillar morphology for PLA fractions above $30 \mathrm{wt} \%$. It was also found that morphologies of calibrated filaments are probably co-continuous between 40 and $60 \mathrm{wt} \%$.

For mono-materials specimens, tensile tests showed that the behavior of the blends was mainly driven by the blend matrix. Due to the low porosity and the fibrillar shape of the polymeric phase of the samples manufactured by fused filament fabrication, their mechanical behavior was determined to be quite similar to those made by injection-molding.

To improve the adherence of PLA/PCL blends on PLA, a superposition of alternating layers of these materials was tested. The advantage of this structure is the increase of the interface area between the PLA and the blend, and the ability to control the gradient of properties between these two materials. It was determined to be stronger than the blend used but displayed the same brittle behavior as pure PLA. In addition, failure always occurred between this structure and the blend region, indicating that the pattern connecting the blend to PLA is not optimal. The application of this blending strategy is nevertheless a promising approach for producing 3D-printing materials with specific properties.

As a result, it was shown that the design proposed in this study is a good way to improve adherence between regions printed with different materials, especially when used with polymer blending. However, the results also showed that this solution could be improved, for instance, by considering existing designs of bonded assemblies. The assembly of multi-materials in additive manufacturing has been drawing the attention of researchers lately, and other solutions have been proposed, like inducing overlap within layers [40] or changing the interphase shape in the $X Y$ plane [41]. A combination of these solutions would be an option to pursue. Eventually, FFF device could also be altered in order to extrude different polymers through the same nozzle [42]. It would enable switching progressively from one polymer to another, thus achieving smoother gradients and excellent interpenetration between materials.

\section{Acknowledgements}

This study was funded by Segula Technologies and IMT Mines Ales. The authors would like to thank Mr. Benjamin Gallard for his assistance in the extrusion experiments, and Mr. Jean-Claude Roux for his support in the microscopy experiments. The authors are also grateful to Dr. Florence Russo and Mr. Jacques Roux-Michollet, for their valuable discussions and their help during this study. Besides, the authors would like to thank Editage (www.editage.com) for English language editing.

\section{References}

[1] Fortelny I., Ujcic A., Fambri L., Slouf M.: Phase structure, compatibility, and toughness of PLA/PCL blends: A review. Frontiers in Materials, 6, 206/1-206/13 (2019). https://doi.org/10.3389/fmats.2019.00206

[2] Patrício T., Glória A., Bártolo P.: Mechanical and biological behaviour of PCL and PCL/PLA scaffolds for tissue engineering applications. Chemical Engineering Transactions, 32, 1645-1650 (2013). https://doi.org/10.3303/CET1332275

[3] Chen R. K., Jin Y-A., Wensman J., Shih A.: Additive manufacturing of custom orthoses and prostheses - A review. Additive Manufacturing, 12, 77-89 (2016). https://doi.org/10.1016/j.addma.2016.04.002

[4] Caliendo C., Langella C., Santulli C., Bove A.: Hand orthosis designed and produced in DIY biocomposites from agrowaste. Design for Health, 2, 211-235 (2018). https://doi.org/10.1080/24735132.2018.1500784

[5] Yeh J-T., Wu C-J., Tsou C-H., Chai W-L., Chow J-D., Huang C-Y., Chen K-N., Wu C-S.: Study on the crystallization, miscibility, morphology, properties of poly (lactic acid)/poly( $\varepsilon$-caprolactone) blends. Polymer-Plastics Technology and Engineering, 48, 571-578 (2009). https://doi.org/10.1080/03602550902824390

[6] Broz M., VanderHart D. L., Washburn N. R.: Structure and mechanical properties of poly(D,L-lactic acid) poly ( $\varepsilon$-caprolactone) blends. Biomaterials, 24, 4181-4190 (2003).

https://doi.org/10.1016/S0142-9612(03)00314-4

[7] Ostafinska A., Fortelný I., Hodan J., Krejčíková S., Nevoralová M., Kredatusová J., Kruliš Z., Kotek J., Šlouf M.: Strong synergistic effects in PLA/PCL blends: Impact of PLA matrix viscosity. Journal of the Mechanical Behavior of Biomedical Materials, 69, 229-241 (2017).

https://doi.org/10.1016/j.jmbbm.2017.01.015

[8] Noroozi N., Schafer L. L., Hatzikiriakos S. G.: Thermorheological properties of poly ( $\varepsilon$-caprolactone)/polylactide blends. Polymer Engineering and Science, 52, 2348-2359 (2012).

https://doi.org/10.1002/pen.23186 
[9] Wu D., Zhang Y., Zhang M., Zhou W.: Phase behavior and its viscoelastic response of polylactide/poly( $\varepsilon$-caprolactone) blend. European Polymer Journal, 44, 2171 2183 (2008).

https://doi.org/10.1016/j.eurpolymj.2008.04.023

[10] Simões C. L., Viana J. C., Cunha A. M.: Mechanical properties of poly( $\varepsilon$-caprolactone) and poly(lactic acid) blends. Journal of Applied Polymer Science, 112, 345 352 (2009).

https://doi.org/10.1002/app.29425

[11] Urquijo J., Guerrica-Echevarría G., Eguiazábal J. I.: Melt processed PLA/PCL blends: Effect of processing method on phase structure, morphology, and mechanical properties. Journal of Applied Polymer Science, 132, 42641/1-42641/9 (2015).

https://doi.org/10.1002/app.42641

[12] Buxton G. A., Balazs A. C.: Predicting the mechanical properties of binary blends of immiscible polymers. Interface Science, 11, 175-186 (2003).

https://doi.org/10.1023/A:1022170627728

[13] Feng X-Q., Mai Y-W., Qin Q-H.: A micromechanical model for interpenetrating multiphase composites. Computational Materials Science, 28, 486-493 (2003). https://doi.org/10.1016/j.commatsci.2003.06.005

[14] Lin W., Shen H., Xu G., Zhang L., Fu J., Deng X.: Single-layer temperature-adjusting transition method to improve the bond strength of 3D-printed PCL/PLA parts. Composites Part A: Applied Science and Manufacturing, 115, 22-30 (2018).

https://doi.org/10.1016/j.compositesa.2018.09.008

[15] Kim H., Park E., Kim S., Park B., Kim N., Lee S.: Experimental study on mechanical properties of singleand dual-material 3D printed products. Procedia Manufacturing, 10, 887-897 (2017).

https://doi.org/10.1016/j.promfg.2017.07.076

[16] Popescu D., Zapciu A., Amza C., Baciu F., Marinescu R.: FDM process parameters influence over the mechanical properties of polymer specimens: A review. Polymer Testing, 69, 157-166 (2018). https://doi.org/10.1016/j.polymertesting.2018.05.020

[17] Lopes L. R., Silva A. F., Carneiro O. S.: Multi-material $3 \mathrm{D}$ printing: The relevance of materials affinity on the boundary interface performance. Additive Manufacturing, 23, 45-52 (2018).

https://doi.org/10.1016/j.addma.2018.06.027

[18] Khudiakova A., Arbeiter F., Spoerk M., Wolfahrt M., Godec D., Pinter G.: Inter-layer bonding characterisation between materials with different degrees of stiffness processed by fused filament fabrication. Additive Manufacturing, 28, 184-193 (2019). https://doi.org/10.1016/j.addma.2019.05.006

[19] Li W., Bakhtiary Noodeh M., Delpouve N., Saiter J-M., Tan L., Negahban M.: Printing continuously graded interpenetrating polymer networks of acrylate/epoxy by manipulating cationic network formation during stereolithography. Express Polymer Letters, 10, 1003-1015 (2016).

https://doi.org/10.3144/expresspolymlett.2016.93
[20] Fischer E. W., Sterzel H. J., Wegner G.: Investigation of the structure of solution grown crystals of lactide copolymers by means of chemical reactions. KolloidZeitschrift und Zeitschrift für Polymere, 251, 980-990 (1973). https://doi.org/10.1007/BF01498927

[21] Wu W., Giese R. F. Jr., van Oss C. J.: Evaluation of the Lifshitz-van der Waals/acid-base approach to determine surface tension components. Langmuir, 11, 379-382 (1995). https://doi.org/10.1021/la00001a064

[22] Owens D. K., Wendt R. C.: Estimation of the surface free energy of polymers. Journal of Applied Polymer Science, 13, 1741-1747 (1969). https://doi.org/10.1002/app.1969.070130815

[23] Żenkiewicz M.: Methods for the calculation of surface free energy of solids. Journal of Achievements in Materials and Manufacturing Engineering, 24, 137-145 (2007).

[24] Wu S.: Calculation of interfacial tension in polymer systems. Journal of Polymer Science Part C: Polymer Symposia, 34, 19-30 (1971). https://doi.org/10.1002/polc.5070340105

[25] Yang J-M., Chen H-L., You J-W., Hwang J. C.: Miscibility and crystallization of poly(L-lactide)/poly(ethylene glycol) and poly(L-lactide)/poly( $\varepsilon$-caprolactone) blends. Polymer Journal, 29, 657-662 (1997). https://doi.org/10.1295/polymj.29.657

[26] Paul D. R., Barlow J. W.: Polymer blends. Journal of Macromolecular Science Part C: Polymer Reviews, 18, 109-168 (1980). https://doi.org/10.1080/00222358008080917

[27] Kitayama N., Keskkula H., Paul D. R.: Reactive compatibilization of nylon 6/styrene-acrylonitrile copolymer blends. Part 1. Phase inversion behavior. Polymer, 41, 8041-8052 (2000). https://doi.org/10.1016/S0032-3861(00)00156-7

[28] Steinmann S., Gronski W., Friedrich C.: Cocontinuous polymer blends: Influence of viscosity and elasticity ratios of the constituent polymers on phase inversion. Polymer, 42, 6619-6629 (2001).

https://doi.org/10.1016/S0032-3861(01)00100-8

[29] Omonov T. S., Harrats C., Moldenaers P., Groeninckx G.: Phase continuity detection and phase inversion phenomena in immiscible polypropylene/polystyrene blends with different viscosity ratios. Polymer, 48, 59175927 (2007).

https://doi.org/10.1016/j.polymer.2007.08.012

[30] Utracki L. A.: On the viscosity-concentration dependence of immiscible polymer blends. Journal of Rheology, 35, 1615-1637 (1991).

https://doi.org/10.1122/1.550248

[31] Barnes H. A.: A review of the rheology of filled viscoelastic systems. Rheology Reviews 2003, 1, 1-36 (2003). 
[32] Ang K. C., Leong K. F., Chua C. K., Chandrasekaran M.: Investigation of the mechanical properties and porosity relationships in fused deposition modelling-fabricated porous structures. Rapid Prototyping Journal, 12, 100-105 (2006).

https://doi.org/10.1108/13552540610652447

[33] Rahim T. N. A. T., Abdullah A. M., Md Akil H., Mohamad D., Rajion Z. A.: The improvement of mechanical and thermal properties of polyamide $123 \mathrm{D}$ printed parts by fused deposition modelling. Express Polymer Letters, 11, 963-982 (2017).

https://doi.org/10.3144/expresspolymlett.2017.92

[34] Reuss A.: Berechnung der Fließgrenze von Mischkristallen auf Grund der Plastizitätsbedingung für Einkristalle. ZAMM - Zeitschrift für Angewandte Mathematik und Mechanik, 9, 49-58 (1929).

https://doi.org/10.1002/zamm.19290090104

[35] Voigt W.: Ueber die Beziehung zwischen den beiden Elasticitätsconstanten isotroper Körper. Annalen der Physik, 274, 573-587 (1889). https://doi.org/10.1002/andp.18892741206

[36] Mori T., Tanaka K.: Average stress in matrix and average elastic energy of materials with misfitting inclusions. Acta Metallurgica, 21, 571-574 (1973). https://doi.org/10.1016/0001-6160(73)90064-3
[37] Xie Z., Sheng J., Wan Z.: Mechanical properties and morphology of polypropylene/polystyrene blends. Journal of Macromolecular Science Part B: Physics, 40, 251-261 (2001). https://doi.org/10.1081/MB-100001813

[38] Halpin Affdl J. C., Kardos J. L.: The Halpin-Tsai equations: A review. Polymer Engineering and Science, 16, 344-352 (1976).

https://doi.org/10.1002/pen.760160512

[39] Guessasma S., Belhabib S., Nouri H.: Understanding the microstructural role of bio-sourced 3D printed structures on the tensile performance. Polymer Testing, 77, 105924/1-105924/14 (2019).

https://doi.org/10.1016/j.polymertesting.2019.105924

[40] Fernández P., Pelayo F., Ávila D., Beltrán N., Blanco D.: Failure analysis of bi-material FFF parts. Procedia Manufacturing, 41, 571-578 (2019). https://doi.org/10.1016/j.promfg.2019.09.044

[41] Roach D. J., Hamel C. M., Dunn C. K., Johnson M. V., Kuang X., Qi H. J.: The m4 3D printer: A multi-material multi-method additive manufacturing platform for future 3D printed structures. Additive Manufacturing, 29, 100819/1-100819/11 (2019). https://doi.org/10.1016/j.addma.2019.100819

[42] Kennedy Z. C., Christ J. F.: Printing polymer blends through in situ active mixing during fused filament fabrication. Additive Manufacturing, in press, 101233/1101233/32 (2020). https://doi.org/10.1016/j.addma.2020.101233 